\title{
Mordet på Ross Marvin - ett problem i internationell straffrätt
}

\author{
Av länsåklagare KLAS LITHNER, Karlskrona
}

År 1961 utkom i London en bok vid namn Encyclopaedia of Murder av Colin Wilson och Pat Pitman. Av författarna är Wilson en ganska känd yngre engelsk författare, som förutom en mängd skönlitteratur också skrivit ett skådespel om Strindberg och en bok om Jack Uppskäraren ${ }^{1}$ ), medan Pitman icke förekommer i Who's Who. Boken utkom 1964 i billighetsupplaga på förlaget Pan Books, och det är i den senare upplagan som jag citerar den. Den innehåller en sammanställning i alfabetisk ordning efter gärningsmännens namn av 300 mord. Vissa av beskrivningarna gälla de gamla vanliga paradnumren, som tröskats igenom av ett otal engelska och amerikanska författare, som t. ex. Lizzie Borden, Madame de Brinvilliers, Bruno Hauptmann och George Joseph Smith. Andra åter äro helt nya för mig, trots att jag i många år samlat på böcker av denna kategori, t. ex. Mrs. Styllo Christofi, Max Gufler och Lorna Lax. Författarna ha tydligen icke lagt ned något eget forskningsarbete utan endast kompilerat vad andra skrivit, ehuru deras litteraturförteckning är långtifrån fullständig. En del av beskrivningarna äro så kortfattade att de bli praktiskt taget meningslösa, t. ex. flera fall, där referatet är ytterst svävande i alla detaljer och något brott ej är fullt bevisat. Vidare innehåller boken en sammanställning av de använda mordmetoderna (s. 661-665) och två essayer av de båda utgivarna om mordet som litterärt studieobjekt enligt metoden tes och antites (s. 15-53). Det enda fall som hämtats från Skandinavien gäller de båda svenska mördarna von Arbin och Kreuger, som år 1923 sprängde en kompanjon i luften för att åtkomma hans livsförsäkring, till vilken de voro förmångstagare (s. 376). Det var den s.k. Flyborgska smällen, som ur juridisk synpunkt är av intresse, därför att det är det grundläggande rättsfallet i Sverige, när det gäller straffrättsligt ansvar vid eventuellt uppsåt. Referatet uppger felaktigt att brottet förövades den $31 / 31923$, medan det i själva verket var den $12 / 31926^{2}$ ).

1) Se Who's Who 1969 s. 3359 .

2) Se NJA I 1927:1 och Nils Jareborg, Handling och uppsåt (1969), s. 228. Fallet har skildrats närmare av Sixten Ahrenberg och Carl-Olof Bernhardsson, Polisen lägger pussel (1951), s. 251-262. 
Det finns emellertid ett annat brott refererat i boken, som via Grönland har anknytning till Skandinavien och som är anledningen till denna artikel. Dess särskilda intresse ligger dock främst i ett uttalande av författarna, som förefallit mig egendomligt. Det strider nämligen mot den grundläggande principen i straffrätten, att det icke finns någon del av jordklotet, som icke är underkastad någon stats territoriella kompetens i straffrättsligt hänseende ${ }^{3}$ ). Fallet refereras kortfattat på s. 439 under offrets namn ,Murder of Ross Marvin“. I tillämpliga delar lyder det sålunda: „Under Robert Pearys Nordpolsexpedition år 1909 lämnade en patrull, bestående av Marvin samt de båda eskimåerna Kudlooktoo och Inukitsaq, huvudexpeditionen för att återvända till dess basfartyg Roosevelt, som låg vid Ellesmere Land (i nordligaste Kanada, min anmärkning). Vid återkomsten dit fick Peary höra av de båda eskimåerna att Marvin drunknat. 1926 vände sig de båda eskimåerna till den danske missionären Jens Olsen och erkände, att de skjutit Marvin, därför att han blivit ,ice-mad“"3a). Historien väckte tvivel, men de båda eskimåerna hade erkänt mord i ett land, över vilket det icke fanns någon laglig kontroll. Det var därför omöjligt att lagföra de båda mördarna, som erkänt sitt brott"“.

Det är sistnämnda uttalande, om avsaknaden av laglig kontroll, som jag fäst mig vid. På fråga till Wilson i brev om hans juridiska källa för uttalandet, har han svarat att det var hans medförfattare Pitman, som ensam svarat för detta referat. Hon i sin tur har icke svarat på en förfrågan därom.

Enligt tillförlitliga källor var bakgrunden för händelsen följande. Den amerikanske mariningenjören Robert E. Peary hade från 1891 företagit flera arktiska expeditioner. 1908 startade han sin sjätte och största expedition med ångafartyget Roosevelt i syfte att nå Nordpolen med start från halvön Grant Land på den stora ön Ellesmere Land i nordligaste Kanada ${ }^{4}$. Bland deltagarna i expeditionen var den amerikanske geologen Ross Marvin, född 1875, från Cornell University. På vägen gjorde Peary uppehåll på Grönlands nordvästkust och tog ombord ett antal eskimåer, som han haft kontakt med och hjälp av vid sina tidigare expeditioner. De kallas omväxlande polareskimåer och Whale Sound-eskimåer. De bodde mellan Cape York och Etah på nämn-

3) Se om „Antarctic Convention“ Fannie J. Klein och Daniel Wilkes, United Nations Draft Statute for an International Criminal Court, s. 583, i Gerhard O. W. Mueller och Edward M. Wise (utg.), International Criminal Law (1965), recenserad NTfK 1966: 201-203.

3a) Om olika typer av "ice-madness" hos sibiriska infödingar se M. A. Czaplicka, Aboriginal Siberia. A Study in Social Anthropology (Oxford 1914), Ch. XV “Arctic Hysteria”, s. 307-325.

4) Se Robert E. Peary, The North Pole (London 1910), flerstädes. 
da kuststräcka. Peary uppger (s. 54) att de skilja sig mycket från eskimåerna på danska Grönland ${ }^{5}$ ). Eskimåerna skulle deltaga i expeditionen som medhjälpare, kuskar för hundspannen och jägare. Bland desso funnos två män, en vid namn Koodlooktoo och den andre nämnes i hans bok endast vid sitt öknamn „Harrigan“. I november 1908 nådde expeditionen Cape Sheridan på Grant Land, där fartyget kvarstannade. Expeditionen och dess förråd förflyttades därefter med hundsläde till den nordligaste udden på Grant Land, Cape Columbia. Därifrån startade polarexpeditionen den 15/2 1909 efter en mycket väl förberedd plan. Den bestod av ett stort antal patruller, var och en med en expeditionsdeltagare som ledare och ett antal eskimåer som kuskar för hundspannen. Dessa patruller ryckte fram längre och längre och lade upp förråd för återfärden. Efterhand återvände de svagare patrullerna, som gått före och banat väg. Den $26 / 3$ återvände den tredje patrullen från slutet, från $86^{\circ} 38^{\prime} \mathrm{N}$, bestående av Marvin och de båda eskimåerna Koodlooktoo och „Harrigan“. Deras mål var högkvarteret vid Cape Columbia. Sedan en ytterligare patrull återvänt, nådde Peary själv tillsammans med sin assistent Matt Henson och fyra eskimåer Nordpolen den 6/4, varefter de omedelbart återvände till Cape Columbia, dit de nådde den 23/4. Där möttes de av den sorgliga underrättelsen att Marvin drunknat. De båda eskimåerna berättade, att de på morgonen den $10 / 4$ skolat starta från ett nattläger på polarisen på en punkt, som beräknades till cirka $84^{\circ} \mathrm{N}$ eller cirka 45 engelska mil norr om Cape Columbia. Marvin hade gått i förväg och hade trampat genom nyisen på en stor vak. Då de kommo dit, var han redan död, och de kunde inget göra. Det var sålunda endast detta dödsfall, som grumlade expeditionens lycka över den uppnådda framgången.

Det nästa som inträffade var följande. 1926 blev Koodlooktoo döpt och erkände att han skjutit Marvin. Detta bekräftades av „Harrigan“. Den förre uppgav som skäl att Marvin blivit ond på „Harrigan“ för något som denna gjort, och att Koodlooktoo handlat $\mathrm{i}$ en nödsituation för att rädda sin kamrats liv. Förklaringen blev dock icke trodd av de kvarlevande expeditionsmedlemmarna. Skillnaden mot Wilsons och Pitmans skildring är dock att enligt de förra mordet förövats av båda eskimåerna gemensamt, enligt Hobbs' bok däremot endast av Koodlooktoo ${ }^{6}$ ). Inukisaq förekommer dock både i Pearys och Hobbs' böcker endast under öknamnet „Harrigan“. Varifrån Wilson och Pitman fått hans riktiga namn framgår däremot inte.

5) För en kortfattad översikt av den historiska utvecklingen se Mads Lidegaard, Det gælder Grönland (1968), s. 48-50.

6) Se William Herbert Hobbs, Peary (New York 1936), s. 347 samt New York Times den 25/9 1926, s. $1-2$. 
I den enda andra biografi över Peary, som jag lyckats få tillgång till, behandlas över huvud taget ej det uppgivna mordet på Marvin. Författaren nöjer sig istället med att argumentera mot Pearys påstående att han nått Nordpolen ${ }^{7}$ ).

Den journalist, George Putnam, som författat den i not 6) nämnda artikeln i New York Times, har också behandlat saken något utförligare i en biografi över sjökaptenen Robert Bartlett (1875-1946) från Newfoundland. Denne var befälhavare på Pearys expeditionsfartyg Roosevelt dels vid dennes framgångsrika färd 1909 och dels vid flera andra polarexpeditioner ${ }^{8}$ ). Putnams skildring i biografin innehåller i korthet följande efter ett föregående referat av vad som 1909 var känt om Marvins död. 1925 bodde Kudlooktoo i Karnah vid Inglefield Gulf norr om Thule på Grönland. Han blev kristen och lät döpa sig. Därefter berättade han sanningen först för sin familj, sedan för missionären Jens Olsen och slutligen för Putnam med den kände polarforskaren Knud Rasmussen som tolk under den expedition, som gjordes 1926 på Bartletts fartyg Morrissey på uppdrag av American Museum of Natural History. Även Inukitsoq berättade en därmed överensstämmande historia för Putnam och Rasmussen. Denna gick alltså ut på att Kudlooktoo skjutit Marvin för att rädda Inukitsoqs liv, då Marvin blivit ond på denne och ville köra bort honom från de båda andra utan livsmedel. Putnam beslöt sig i samråd med Bartlett för att offentliggöra historien.

Ur juridisk synpunkt var det ett problem, om polarisen kunde jämföras med öppna havet som plats för ett brott, när de berörda personerna ej färdades ombord på ett fartyg utan gingio eller åkte på isen. Vidare var det ett problem, om polarisens normala sammanhängande med Grönland gjorde att den kunde betraktas som en utlöpare därav ur territoriell synpunkt. Detsamma kunde f.ö. även gälla beträffande Kanada. 1909 var landet norr om Melville Bay på Grönland i ordets verkliga mening ett ingen mans land, vars enda kontakt med yttervärlden utgjordes av besöken av Peary och andra upptäcktsresande. Därför beslöto Putnam och Bartlett gemensamt enligt den förres uppgift att gärningen sannolikt icke kunde föranleda någon åtgärd.

Om Putnam var journalist eller forskningsresande har jag ej lyckats få uppgift om. I den i not 6) nämnda utförliga artikeln i New York Times av Putnam nämnes att Inukitsoq vid tiden för händelsen 1909 var 19 år enligt uppgift av Pearys medhjälpare

7) Se J. Gordon Hayes, Robert Edwin Peary (London 1929).

s) Se George Palmer Putman, Mariner of the North. The Life of Captain Bob Bartlett (1947), s. 92, 95 och 187-194.

9) Se Knud Rasmussen, Norr om människor (1919), s. 116 m. fl. På s. 181 och 421 finns porträtt av Inukitsoq. Se vidare mera kortfattat Knud Rasmussen, Polarforskningens saga (1932), s. 296-297. 
Matt Henson. Putnams tolk och sagesman i vissa avseenden Knud Rasmussen hade grundat handelsstationen Thule på nordvästra Grönland, som blev utgångspunkten för Danmarks herravälde däröver. I Rasmussens egen skildring av den andra Thuleexpeditionen 1916 - 17, då den svenske deltagaren docent Thorild Wulff dog den 29/8 1917 av svält och utmattning vid Humboldtglaciären på nordvästra Grönland, finns en utförlig och mycket fördelaktig skildring av Inukitsoq. Enligt Rasmussen (s. 181) betecknas han dock 1917 som ung, och det uppges, att han fått sitt elddop under den första Thuleexpeditionen 1912. Detta gör det föga troligt att han redan 1909 skulle ha varit kvalificerad att deltaga i Pearys Nordpolsexpedition med ansvarsfulla uppgifter. Det även hos Rasmussen flera gånger förekommande öknamnet „Harrigan“" visar dock att det måste vara fråga om samme person.

Genom dessa från olika håll införskaffade uppgifter får sakförhållandet sålunda anses utrett. Då återstår till bedömande den juridiska frågan om det varit möjligt att ingripa mot gärningsmannen eller -männen, antingen 1909 i samband med brottets förövande eller 1926 efter erkännandet. Tre möjligheter till ingripande kunde i varje fall teoretiskt föreligga, nämligen med stöd av amerikansk lag på grund av offrets nationalitet, på Grönland med stöd av dansk lag eller i Kanada på grund av gärningsortens geografiska anknytning dit. Innan jag ingår härpå, skall jag emellertid som jämförelse först kortfattat nämna de gällande svenska regler som äro tillämpliga på motsvarande situation. Enligt den nu gällande regeln kan jämlikt $\mathrm{BrB} 2: 33$ p. utländsk medborgare dömas vid svensk domstol för brott, som han utom riket förövat mot svensk medborgare. Åtal kräver jämlikt BrB 2:5 1 st. Konungens tillstånd. Av kommentaren till BrB 2:2 2 st. framgår vidare, att om någon lag ej gällde å gärningsorten, t. ex. å öppna havet utanför staternas territorialvatten, detta icke utesluter att svensk strafflag är tillämplig och svensk domstol kompetent $\left.^{10}\right)$. Före Brottsbalkens införande var förhållandet annorlunda ${ }^{11}$ ). Agge gör sålunda ett uttalande (s. 73 a.a.), som väl skulle passa in på det aktuella fallet, nämligen att inskränkning i nationalitetsgrundsatsen kan föranledas av billighetsskäl, t. ex. hänsyn till de speciella seder och förhållanden (kursiverat av mig) som råda i gärningslandet.

Vad angår möjligheten att tillämpa amerikansk lag mot gärningsmannen på grund av offrets amerikanska medborgarskap

10) Se kommentaren till BrB I, 2 uppl., s. 67 och Hans Thornstedt, Svensk medborgares ansvar för brott utomlands, SvJT 1966:507 och 514 not 29.

11) Se Ivar Agge, Den svenska straffrättens allmänna del i huvuddrag, häfte 1 (1944), s. 70-76 och 82-85, samt Nils Beckman, Svensk domstolspraxis i internationell rätt (1959), s. 13. 
äro förhållandena följande. I den amerikanska doktrinen ha olika principer diskuterats för att kunna läggas till grund för den territoriella straffrättsliga jurisdiktionen. En av dessa principer är den s.k. passiva personprincipen, $d$ v s den som utgår från offrets nationalitet. Det finns emellertid inget belägg för att denna godtagits i amerikansk rätt så tidigt som 1909. I en senare artikel har emellertid föreslagits, att en stat borde ha jurisdiktion beträffande ett brott, som förövats utanför dess gränser av en utländsk medborgare, om brottet förövats på en plats, som ingen stat hade myndighet över, och brottet förövats mot förstnämnda stat eller en av dess undersåtar ${ }^{12}$ ). Det är sålunda mycket tvivelaktigt, om en amerikansk domstol skulle ha ansett sig behörig. I så fall skulle det $\mathrm{i}$ varje fall ha varit en federal domstol, eftersom brottet förövats utom USA:s gränser. Detta är dock också osäkert, eftersom den tillämpliga territoriella behörighetsregeln gällde brott, som förövats inom USA:s militära eller sjörättsliga maktområde eller områden, som förvärvats på USA:s räkning och varöver denna stat ensam hade jurisdiktion. Det kan emellertid också tänkas, att en federal domstol skulle ha ansett att territoriell kompetens följt av att Pearys amerikanska expedition utgjorde den enda faktiskt existerande maktfaktorn i detta område. Vad slutligen angår frågan om vilka åtgärder som kunde ha vidtagits år 1926, då brottet upptäcktes genom Koodlooktoos erkännande, förelåg ingen preskriptionstid för ,,first degree murder", medan preskriptionstiden för ",second degree murder" eller „manslaughter“ var tre år $\left.{ }^{13}\right)$. Det förefaller föga troligt att en amerikansk domstol år 1926 skulle ha ansett ett uppsåtligt dödande av Marvin, förövat 1909 av den ene eller båda eskimåerna, under de ytterst speciella förhållanden som förelågo, såsom ,first degree murder". Sistnämnda brott definineras på följande sätt i den amerikanska federala strafflagen i ett något otympligt försök till översättning: „Varje mord, som förövats med hjälp av gift, genom att ligga i försåt eller varje annat slag av avsiktligt, uppsåtligt, onskefullt och överlagt dödande; eller som begåtts under förövande av eller försök att föröva mordbrand, våldtäkt, inbrottsstld eller rån; eller som förövats enligt en beslutad plan att olagligen och med ont uppsåt åstadkomma någon annan människas död än den som dödas, är mord av första graden“"14).

12) Se Harvard Research on International Law, Part III, Jurisdiction with Respect to Crime, 1935 (29), American Journal of International Law, Supplement s. 435.

13) För dessa upplysningar om amerikansk rätt står jag i tacksamhetsskuld till professor Gerhard O. W. Mueller och forskningsassistenten Janet Calvo vid New York University Law School, av vilka den senare tillhandahållit ett värdefullt forsknings-PM.

14) Se Royal Commission on Capital Punishment 1949-1953 Report (1953), s. 440. 
När det gäller möjligheten att tillämpa dansk lagstiftning, är det av avgörande betydelse att Thuleområdet både 1909 och 1926 föll utanför den danska jurisdiktionen på Västgrönland. Först 1929 utfärdades genom Knud Rasmussens initiativ några „lagar“ för Thuleområdet. Däri fanns en straffregel för den som förbröt sig mot samfundet och en annan regel om att en mördare skulle. gripas och föras till Thulestationen. Vidare fanns en mycket vidsträckt straffrihetsregel för nödvärns- och nödsituationer. 1909 och 1926 fanns däremot varken straff- eller processrättsliga regler för Thuleområdet. Följaktligen hade möjlighet uppenbarligen saknats att vid dessa båda tidpunkter eller i efterhand, alltså 1929, tillämpa dansk lag på gärningen ${ }^{15}$ ).

När det slutligen gäller möjligheten att tillämpa kanadensisk lag, är läget följande. Förutsättningen för en rättegång i Kanada var att brottet ägt rum i detta land, inom ett område, på vilket landet gjorde anspråk, inom en sjömil från kusten eller på ett kanadensiskt fartyg. Så var emellertid icke förhållandet med mordet ifråga. På grund av det juridiska förhållandet mellan moderlandet Storbritannien och „Dominion of Canada“ hade det däremot varit möjligt att åtala eskimåerna i Kanada, om Storbritannien gjort anspråk på överhöghet över denna del av polarkalotten. Åtalet skulle i så fall ha gällt brott mot engelsk ,Common Law", nämligen mord. Detta skulle dock ha krävt samtycke av den brittiske generalguvernören i Kanada som Storbritanniens officielle representant. Ingen av dessa förutsättningar var heller uppfylld. Följaktligen saknades även denna möjlighet för ingripande. Det fanns däremot ingen preskriptionstid för mord i Kanada, varför det teoretiskt sett hade varit möjligt att 1926 ingripa mot ett mord, som förövats $1909^{16}$ ).

Av det sålunda anförda synes alltså framgå, att Wilsons och Pitmans uttalande är riktigt ur juridisk synpunkt, och att gärningen faktiskt var straffri, då territoriell kompetens saknades för alla tänkbara länder, $i$ varje fall då händelsen inträffade.

Det kan tilläggas, att sedan manuskriptet förelåg färdigt, har jag genom förmedling av professor Jayewardene fått tillgång till en artikel av en professor i civilrätt vid University of Ottawa, som refererar ett färskt rättsfall. Enligt detta, det s.k. Escamillafallet från 1970, är en vetenskaplig forskningsstation på en fly-

15) För dessa upplysningar står jag i tacksamhetsskuld till professor Knud Waaben, Köbenhavn, och professor emeritus, dr. phil. Erik Holtved, Hareskovby. Jämför även „Kundgörelser vedrörende Grönlands Styrelse 1938-1947“ (1948), s. 91 ff. samt Verner Goldschmidt, Kriminalitet i Thule, NTfK 1950:12-22.

16) För dessa upplysningar står jag i tacksamhetsskuld till läraren i straffrätt, domaren Livius Sherwood och professorn i kriminologi C. H. S. Jayewardene, Center of Criminology, University of Ottawa, Kanada. 
tande isö i Polarhavet att jämställa med ett fartyg från den nation som utrustat expeditionen, alltså i detta fall USA. Trots att händelsen inträffat inom Kanadas sektor av polarkalotten, godtogo de kanadensiska myndigheterna stillatigande att en amerikansk medborgare, som dödat en annan amerikan under sådana omständigheter, fördes till USA för att ställas inför federal domstol där $\left.{ }^{17}\right)$.

Klas Lithner

17) Se Donat Pharand, State Jurisdiction over Ice Island T-3: The Escamilla Case, Arctic (Journal of the Arctic Institute of North America), Vol. 24, Nr. 2, June 1971, s. $83-89$. 